\title{
EL ANÁLISIS NARRATOLÓGICO CLÁSICO
}

Willard Diaz

\section{RESUMEN}

El Análisis de Textos es la herramienta más usual en el trabajo académico universitario en los campos de la Literatura y la Educación. Bajo su nombre se agrupan teorías y metodologías diversas que fueron surgiendo a lo largo del siglo XX y que tuvieron su origen en los estudios de los llamados Formalistas Rusos.

Aquí presento, a la manera de Apuntes de Clase (para dos sesiones), un apretado resumen de la primera de dichas metodologías, la formalista, seguida de una muestra de su aplicación a una popular película.

\section{EL MODELO DE VLADIMIR PROPP}

- Fueron los formalistas rusos quienes a comienzos del siglo XX propusieron el estudio formal de la obra literaria, en su deseo de superar a las aproximaciones contenidistas y contextuales psicológicas, sociológicas o históricas en uso. Tinianov, Eichenbaum, Brick, Shklovski, Jakobson y otros trataron de realizar un estudio centrado estrictamente en la obra misma.

- Partieron de la hipótesis de que se podía hacer una descripción técnica de la obra.

- En 1928 Vladimir Propp publica su "Morfología del cuento", que sólo se conoce fuera de Rusia en 1958. Su traducción al francés por Todorov, y luego al inglés, tuvo gran influencia en los estudios estructurales narratológicos europeos.
- Vladimir Propp se propuso estudiar los cuentos folclóricos fantásticos rusos con este método. Su primera tarea fue hacer una selección y una clasificación de los cuentos. Otros investigadores rusos habían usado criterios históricos o de contenido o temáticos; Propp decide limitarse a los elementos formales, pero encuentra que los conceptos morfológicos no son muy claros.

- Al analizar los cuentos fantásticos elegidos notó que casi todos tenían una serie de acontecimientos parecida, incluso cuando las motivaciones variaban. Descubrió así que la unidad de la narración estaba en la forma común a todos los cuentos, no en el contenido; y la llamó función.

- Función, según Propp, es "la acción de un personaje definida desde el punto de vista de su significado en el desarrollo de la intriga". 
- En la función no importan tanto el contenido específico ni los personajes; es sólo un concepto abstracto, definido por su lugar en la intriga.

- Propp encuentra de esta manera que el número de funciones en los cuentos recopilados no era muy grande, aunque los personajes fueran muy variados.

- Notó, además, que el orden de los sucesos tiene unas leyes específicas: primero la princesa es raptada, luego viene su búsqueda, etc.

- Cuando logró extraer el esquema general del conjunto de cuentos elegido advirtió que en algunos podían faltar ciertas funciones, pero que eso no altera el orden de las que sí aparecen.

- Llegó a la conclusión de que "todos los cuentos maravillosos pertenecen al mismo tipo en lo que concierne a su estructura".

- Su lista mínima de funciones fue:

O.Situación inicial: presentación de la familia o del héroe

1. Uno de los miembros de la familia se aleja de la casa (alejamiento)

2. Recae sobre el protagonista una prohibición (prohibición)

3. Se transgrede la prohibición (transgresión)

4. El agresor intenta obtener información [interrogatorio]

5. El agresor recibe noticias sobre su víctima [información]

6. El agresor intenta engañar a su víctima para apoderarse de ella o de sus bienes [engaño]

7. La víctima se deja engañar y ayuda así a su enemigo a su pesar (complicidad).

8.(A) El agresor daña a uno de los miembros de la familia o le causa perjuicios (fechoría).

(a)Algo le falta a uno de los miembros de la familia; desea poseer algo [carencia).

9. Se hace pública la desgracia; el héroe es enviado (mediación, transición)

10. El héroe-buscador acepta o decide actuar (contra acción)

11. El héroe deja la casa (partida)

12. El héroe pasa una prueba, que le prepara para recibir un objeto mágico [primera función del donante].

13. El héroe reacciona ante las acciones del futuro donante (reacción del héroe)

14. El héroe adquiere el objeto mágico (recepción del objeto mágico)

15. El héroe es llevado cerca del lugar en el que se encuentra el objeto de su búsqueda (desplazamiento)

16. El héroe y el villano se encuentran en combate (combate).

17. El héroe recibe una marca (marca)

18. El agresor es vencido (victoria)

19. La fechoría es reparada o la carencia colmada (reparación)

20. El héroe regresa (retorno)

21.El héroe es perseguido (persecución)

22. El héroe es rescatado (socorro).

23. El héroe llega de incógnito a su casa o a otra comarca (llegada de incógnito)

24. El falso héroe reivindica pretensiones infundadas (pretensiones infundadas)

25. Se propone al héroe una tarea difícil (tarea difícil).

26. La tarea es realizada (tarea cumplida).

27(recono. El héroe es reconocido cimiento).

28. El falso héroe o el villano queda descubierto [descubrimiento].

29. El héroe recibe una nueva apariencia (transfiguración).

30. El villano es castigado (castigo).

31.El héroe se casa y asciende al trono (matrimonio). 
Las funciones 1 a 7 son de Preparación; de la 8 a la 10 son de Complicación; de la 11 a la 15, de Transferencia; de la 16 a la 19, de Lucha; de la 20 a la 26, de Retorno; y de la 27 a la 31, de Reconocimiento.

Además de las funciones, Propp encuentra otros elementos en la estructura narrativa: elementos de enlace entre una y otra función, elementos que favorecen la triplicación, y las motivaciones o móviles.

En cuanto a la distribución de las funciones entre los personajes, Propp halló siete "esferas de acción" que pueden ocupar los personajes:

1. El agresor o villano, que crea la complicación narrativa.

2. El donante que le da al héroe algo, sea un objeto, información o consejo, y le ayuda a resolver el problema.

3. El ayudante que auxilia al héroe en su tarea.

4. La princesa (o personaje buscado), que es el personaje más amenazado por el malvado y debe ser salvada por el héroe; y su padre qque en los cuentos fantásticos es a menudo un rey] quien aprueba al héroe y castiga al falso héroe.

5. El mandatario, que ordena al héroe realizar la búsqueda (puede ser el mismo rey].

6. El héroe, usualmente masculino, que restaura el equilibro en el relato, emprende una búsqueda, salva a la princesa y con ello se gana su mano. Propp distinguió entre el "héroe víctima" contra el que se empeña el villano, y el "héroe buscador" que ayuda a otros que son víctimas del villano. El héroe es el protagonista del relato de aventuras.

7. El falso héroe que parece ser bueno pero al final se revela que era malo. No siempre se presenta este personaje.

- Propp descubre que los personajes pueden no sólo una sino varias de las esferas de acción, o las esferas de acción pueden cubrir a más de un personaje. La princesa también puede ser ayudante, o puede haber varios villanos.

- Al distinguir entre las funciones (forma) y los personajes (contenido), Propp separa también dos modelos estructurales: el de la sucesión temporal de las acciones, y el de los personajes.

- Propp llama "secuencia" a "todo desarrollo que partiendo de una fechoría o de una carencia y pasando por las funciones intermedias culmina en el matrimonio o en otras funciones utilizadas como desenlace".

- La única función obligatoria del cuento es la "carencia", según Propp.

- Claude Levi-Strauss criticó el modelo de Propp y se propuso perfeccionarlo. Redujo las 31 funciones a unas pocas, y en lugar del modelo cronológico propone uno lógico estructural. Pero los estructuralistas han apreciado el modelo de Propp y lo han convertido en la base de sus especulaciones.

- En la narrativa cinematográfica se han introducido modelos similares al de Propp, actualizados según la manera de pensar contemporánea. Por ejemplo, ya 
la boda no es esencial.

- En 1985 un guionista de Disney llamado Christopher Vogler presentó un simplificado plan de doce pasos para cintas de héroes inspirado en Propp, que es muy usado en Hollywood y que se puede encontrar en películas como "Matrix", "El Rey León" o "El Príncipe de Persia":

1. En el mundo ordinario.

2. Llamado a la aventura.

3. Rechazo del llamado.

4. Encuentro con un mentor.

5. Cruce del primer umbral.

6. Pruebas, aliados y enemigos.

7. Acercamiento a la cueva recóndita.

8. Pruebas máximas.

9. Premio (posesión de la espada).

10. De nuevo al camino.

11. Resurrección.

12. Retorno con el elixir.

\section{APLICACIÓN A LA PELÍCULA "LA GUERRA DE LAS GALAXIAS, EPISODIO IV"}

1. En el mundo ordinario.

El inquieto adolescente Luke Skywalker está hastiado de su vida en la lejana granja donde vive con sus tíos.

2. Llamado a la aventura.

Por casualidad Luke encuentra el desesperado pedido de ayuda de la princesa Leia que lleva el robot R2D2 a Obi Wan Kenobi.

3. Rechazo del llamado.

Luke halla a Obi Wan Kenobi pero teme aceptar el reto, diciéndose que sus tíos lo necesitan.

4. Encuentro con el mentor.

Luke se pone en manos de Obi Wan y empieza su preparación para entrar en la Fuerza.

5. Cruce del primer umbral.

Luke acepta el desafío cuando las tropas imperiales matan a su familia.

6. Pruebas, aliados, enemigos.

Luke y Obi Wan van al bar del espacio, encuentran a Han Solo y Mascatabaco y se gana el odio de Jabba the Hut.

7. Aproximación a la cueva

Luke y sus amigos tienen una serie de aventuras que culminan en el intento de rescatar de la Estrella de la Muerte a la princesa Leia.

8. Desafío máximo

La prueba máxima está formada por la serie de aventuras en la Estrella de la Muerte, hasta que casi muere en el depósito de basura.

9. Premio (la espada)

Luke y sus amigos huyen con la princesa y la información necesaria para destruir a la Estrella de la Muerte, pero no sin el sacrificio de Obi Wan Kenobi.

10. De regreso al camino No ha pasado lo peor, la Estrella de la Muerte se acerca a la base rebelde, y tiene que ser destruida.

11. Resurrección.

Luke adquiere confianza en la Fuerza, se hace un Jedi, y destruye a la Estrella de la Muerte, a costa de sacrificar su antigua vinculación con las máquinas.

12. Regreso con el elixir. Luke y sus amigos son condecorados como héroes. El elixir que ha ganado Luke es su domino interno de la Fuerza. 


\section{REFERENCIAS BIBLIOGRÁFICAS}

1.Adam, Jean-Michel, (1994) "Le texte narratif", Nathan, París.

2.Barthes, Roland, et al., (1970) "Análisis estructural del relato", Tiempo Contemporáneo, Buenos Aires.

3.Beristáin, Helena, (1994) "Análisis estructural del relato literario", Limusa, Méjico.

4. Erlich, Víctor, (1974) "El formalismo ruso", Seix Barral, Barcelona.

5. Herman, David (Ed.), (1999) "Narratologies", Ohio State University.
6. Prado Oropeza, Renato (Ed.) (1989) "La narratología hoy, Arte y Sociedad", La Habana.

7.Prince, Gerard, (1987) "A Dictionary of Narratology", University of Nebraska Press, USA.

8. Propp, Vladimir, (1985) "Morfología del cuento”, Ed. Fundamentos, Madrid.

9.Segre, Cesare, (1985) "Principios de análisis del texto literario", Crítica, Barcelona.

10. Todorov y otros, (1970) "Teoría de la literatura de los formalistas rusos", Signos, Buenos Aires.

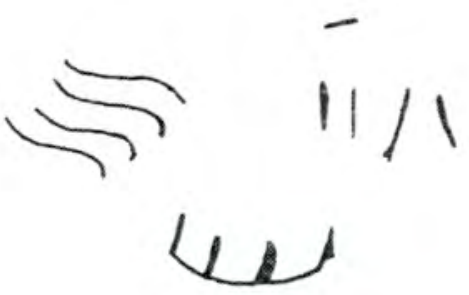

